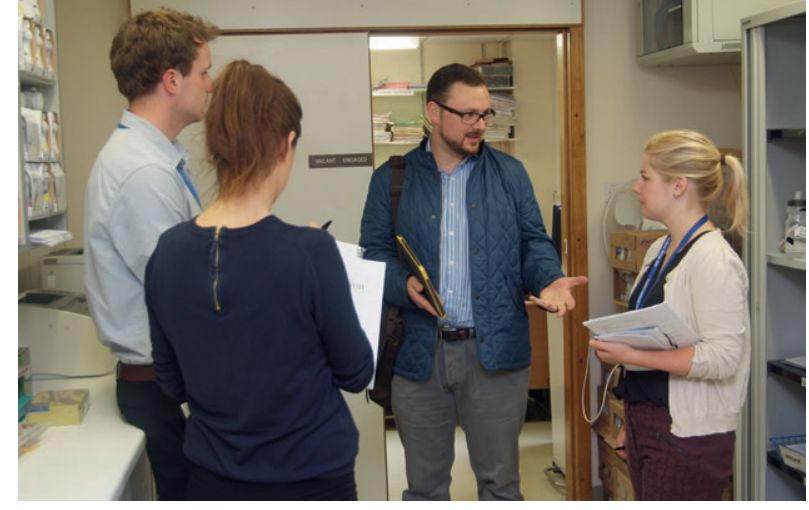

\title{
Handover education improves skill and confidence
}

\section{Jennifer Stojan ${ }^{1,2}$, Patricia Mullan ${ }^{3}$, James Fitzgerald ${ }^{1}$, Monica Lypson ${ }^{3}$, Jennifer Christner ${ }^{4}$, Hilary Haftel ${ }^{2}$ and Jocelyn Schiller ${ }^{2}$}

${ }^{1}$ Department of Internal Medicine, University of Michigan Medical School, Ann Arbor, Michigan, USA

${ }^{2}$ Department of Pediatrics, University of Michigan Medical School, Ann Arbor, Michigan, USA ${ }^{3}$ Department of Medical Education, University of Michigan Medical School, Ann Arbor, Michigan, USA

${ }^{4}$ Department of Pediatrics, Baylor College of Medicine, Houston, Texas, USA

Medical schools

infrequently teach handover skills

\section{SUMMARY}

Background: Despite the frequency of patient-care handovers and vulnerability to errors, medical schools infrequently teach handover skills. Our study evaluated the impact of a medical school handover curriculum on students' performance, as rated by faculty members, peers and self-assessment.

Methods: Nineteen fourth-year medical students participated in a handover curriculum that included a workshop and three directly observed patient handovers, with feedback from faculty members. Multivariate repeated-measures analysis evaluated faculty member, peer, and self-rated performance over time. Students' self-assessed confidence in performing handovers prior to, at the end of, and 8-12 months after the curriculum was also analysed.

Results: Faculty member, peer and self-assessments showed that students' performance significantly improved after the curriculum, on handover content, clinical judgment and overall performance $(p<0.05)$. Students rated the curriculum as effective and characterised themselves as more prepared to perform handovers, with these findings persisting for 8-12 months $(p \leq 0.001)$.

Discussion: A handover curriculum appears to improve medical students' handover performance, as evaluated by independent ratings from faculty members, peers and the students themselves, in addition to improving the students' confidence. 


\section{INTRODUCTION}

 $\mathrm{n}$ order to improve patient safety, the American Council of Graduate Medical Education (ACGME) mandated restricting postgraduate trainee working hours. An unintended consequence was an increase in patient-care handovers, defined as the giving and receiving of patient information between health care providers across shift changes (also referred to as 'handoff' or 'signout'). ${ }^{1}$ Transitions in care introduce vulnerability to communication failures, uncertainty in patient care, delay in diagnosis or treatment, near misses and inefficiencies or work redundancies. ${ }^{2}$ Recognising that communication failures account for the majority of sentinel events, the World Health Organization issued patient-safety mandates requiring standardised approaches to handover education. ${ }^{3}$

Handover education research has focused on the training and assessment of postgraduates. ${ }^{4}$ Despite the importance placed on handover training, studies indicate that ineffective handovers still occur, ${ }^{5}$ and that trainees feel unprepared to perform handovers. ${ }^{6}$ Complicating matters, postgraduate training programmes expect trainees to assume patient-care responsibilities upon entry, prior to any postgraduate training with a handover curriculum. Given that medical school is a trainee's preparation for postgraduate year-1 (PGY-1) responsibilities, medical schools should be teaching handover skills. The Association of American Medical Colleges explicitly identifies giving and receiving patient handovers as a core competency for entering residency; ${ }^{7}$ however, only 35 per cent of medical schools in the USA formally provided handover instruction. ${ }^{8}$ Expecting incoming trainees without adequate preparation to be competent in the handover process is unreasonable.
As fourth-year medical students perform the duties of PGY-1 trainees during subinternship rotations, our paediatric in-patient subinternship provided an opportunity to institute a formal handover training curriculum. The goal of our curriculum was to improve students' performance of the handover process, as assessed by faculty members, peers and the trainees themselves.

\section{METHODS}

\section{Participants}

Fourth-year medical students at a North American universityaffiliated hospital enrolled in a paediatric subinternship in 2012. Students were assigned to an in-patient team during the day. Each week, one student rotated on a block of night shifts. At the end of their day or night shift, students transitioned the care of their patients to another subintern. Each student participated in our handover curriculum, which included a 1-hour workshop and faculty member-observed patient handovers, with feedback, on three separate occasions over the course of 1 month. Our Institutional Review Board granted the study as exempt from review.

\section{Previous training, knowledge and confidence in relation to patient handovers}

Pre- and post-rotation, students completed an assessment eliciting perceptions of knowledge and confidence related to giving and receiving patient handovers. The pre-rotation assessment also included questions about trainees' previous education on the handover process. We also administered a post-rotation assessment at the end of the rotation, and 8-12 months later, immediately prior to graduation from medical school, which included questions evaluating the perceived impact of our curriculum on the handover process.

\section{Workshop}

At the start of the rotation, students participated in a 1-hour workshop demonstrating the importance and components of the handover process. The workshop examined the effects of the ACGME work-hour requirements on handovers, consequences of poor patient handovers and barriers to communication, and recommendations for handover standardisation and training. Handovers as a shared responsibility were also discussed. Students brainstormed qualities of 'good' and 'poor' handovers, and then viewed video examples of each for further discussion. ${ }^{9}$ Faculty members then introduced the SIGNOUT mnemonic as a method to ensure appropriate information is provided during a handover. ${ }^{4}$

\section{Observed handovers}

During the rotation, faculty members observed students transferring the care of patients to a peer on three occasions: the first occasion being prior to handover instruction, with the remaining observations following the handover instruction workshop, at 2-week intervals. For each observation, faculty members provided structured feedback using our assessment tool. Students receiving the handover (peer) and students initiating the handover (self) completed the same assessment tool immediately after the handover, and then the faculty members provided verbal and written feedback.

\section{Assessment tool}

A panel of local experts developed our assessment tool (Table 1), incorporating items from the SIGNOUT tool, ${ }^{4}$ covering content and clinical judgment, and supplementing items from peerreviewed research to incorporate the assessment of organisation and efficiency, communication skills and professionalism. ${ }^{10}$ Medical education experts, faculty members, postgraduate trainees and students provided feedback
Expecting incoming trainees without adequate preparation to be competent in the handover process is unreasonable 
Handover

performance

improved over

the course of the subinternship
Table 1. Performance assessment of the verbal handover, incorporating items from the SIGNOUT tool ${ }^{4}$

Items pertaining to content

S

I

N

0

U

T

Allows for questions
Ideal setting for handover
Organisation/efficiency
Communication skills
Professionalism/attitude

prior to our piloting the tool using actual patient handovers. The final version included 15 items, scored as 'not done' (0), 'done but needs improvement' (1) or 'done well' (2).

\section{Observers}

One of two experienced paediatric clinicians/educators (JNS and JHS) evaluated each handover. Observer training included a series of calibration exercises in which the observers used the observation tool to assess video clips of trainees conducting handovers. Raters discussed discrepancies and explained their scoring. The Cohen Kappa interrater agreement measure indicated high agreement (0.82).

\section{Analysis}

We calculated descriptive statistics for participant demographics, previous related training, and pre- and post-training confidence and performance. We evaluated changes in handover confidence ratings over time using multivariate analyses with repeated measures (F-test). We evaluated differences in performance over time on content, clinical judgment, and overall performance, using multivariate analyses with repeated measures.

\section{RESULTS}

Nineteen students participated in the handover curriculum as part of their paediatric subinternship. Only 16 per cent $(3 / 19)$ of students reported receiving prior handover instruction, and none reported receiving prior feedback. When asked to identify the leading root cause of sentinel events, 84 per cent $(16 / 19)$ of entering students correctly answered 'lapses in communication', with 95 per cent (18/19) answering correctly postcurriculum ( $p=0.03)$.

Overall, 93 individual patient handovers from 15 students over three observations were included in the interpretation of the performance data, with each individual student performing between three and nine patient handovers (mean 6.1, SD 1.7). We excluded from the analysis four students who were on a night block during the first week of the rotation, who participated in the workshop prior to their first observed handover.

The mean self-assessed confidence scores increased significantly during the subinternship ( $p \leq 0.001$; Table 2). Students also characterised themselves as better able to communicate the necessary information in a handover, and to do so more efficiently. These increases in self-assessed confidence persisted 8-12 months later, prior to the students entering their PGY-1 year ( $p \leq 0.001)$.

Handover performance, as evaluated by faculty members, peers and the students themselves, improved over the course of the subinternship (Figure 1). Initial faculty member-derived performance scores were 68 per cent (SD 13\%), but increased to 96 per cent (SD 5\%) by the final observation $(p<0.005)$.

Students rated the curriculum favourably with an overall mean rating of 4.8 on a 5-point Likert scale, in which the higher numbers represented more favourable ratings. When asked to rate the individual components of the curriculum, the students' mean rating for the didactic workshop was 3.9, rating the attending physician's immediate feedback as 4.8.

\section{DISCUSSION}

A recent study of paediatric residency programmes found that programmes struggle to incorporate systematic patient-care handover instruction, with only one in three reporting curricula 
Table 2. Fourth-year medical students' mean self-assessed confidence scores across time $(n=19)$

\author{
Pre-survey Post-survey Follow-up survey $\mathrm{p}^{*}$ \\ (prior to (1 month (8-12 month \\ curriculum) follow-up) follow-up)
}

\section{I can communicate all the information that is needed in a handover}

I can communicate all the information that is needed in a handover in an efficient manner

I am able to take care of acute issues overnight based on $3.0 \pm 0.7$ the handover I receive

I am prepared to perform a handover as a PGY-1 trainee

How would you rate your overall handover performance?

$$
2.3 \pm 0.8
$$$$
1.8 \pm 0.7
$$

$4.3 \pm 0.5$

0.001

$2.6 \pm 0.8$

$4.0 \pm 0.6$

$4.1 \pm 0.5$

$<0.001$

$4.1 \pm 0.6$

$3.8 \pm 0.5$

$<0.001$

$4.3 \pm 0.5$

$4.2 \pm 0.5$

$<0.001$

$4.1 \pm 0.5 \quad 3.9 \pm 0.3$

$<0.001$

*Multivariate analysis with repeated measures, F-test.

Scores are based on a Likert scale from 1 to 5, with higher numbers representing greater confidence.

(a)

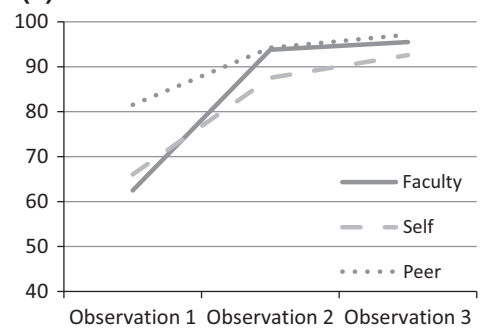

(b)

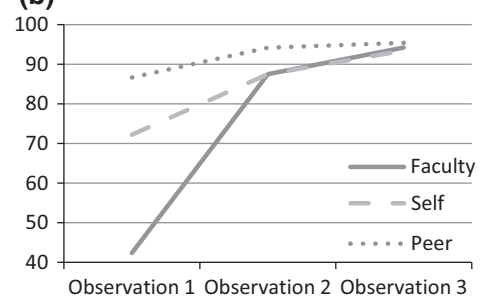

(c)

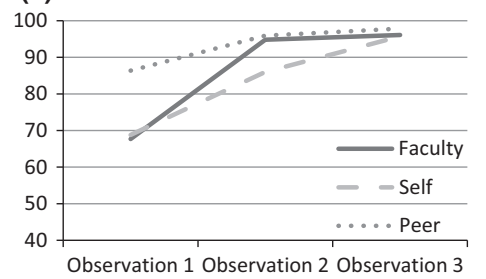

Figure 1. Student handover performance rated over time (observation 1, pre-handover instruction; observations 2 and 3, post-handover instruction) by assessor group (faculty members, peers and the students themselves) on: A, clinical content performance; B, clinical judgment performance; and C, overall performance. For all three analyses, the effect of time had a $p$ value of $<0.001$ and the effect of time $\times$ group had a $p$ value of $<0.05$

with goals, objectives and assessments. ${ }^{11}$ Although efforts to prepare trainees prior to their postgraduate care responsibilities attest to the students' appreciation of such training, evidence of the impact of these interventions might further promote handover training during medical school. ${ }^{12}$ Our study demonstrates that a handover curriculum for medical students seems to be associated with improved clinical skills and confidence. This study adds to the current body of handover research by including pre-instruction data, as we were able to compare pre- and post-intervention performance. We demonstrated an improvement in handover performance after the intervention, with continued improvement as the students progressed through the curriculum. Our study is also unique in that it demonstrated an increase in the students' self-assessed abilities, not only immediately after the curriculum but also 8-12 months later, demonstrating a sustained effect. Our goal is to prepare students to provide handovers as PGY-1 trainees, and therefore the success of this training lies in its ability to sustain long-term impact.

Our findings suggest that training for patient handovers in the fourth year of medical school is feasible in a clinical setting. We were able to integrate our direct observations and feedback on performance into the students' everyday patient care, making the exercise clinically relevant to the learner. As medical education moves to competency evaluation, observation by faculty members will become increasingly necessary. Students rated the curriculum favourably, and felt that the immediate feedback from faculty members was beneficial.

Our study was performed in a single department at one academic institution, and therefore the results may not be generalisable to students at other medical schools or in other departments. In addition, only 19 medical students were assessed, reflecting the limited number of students rotating through a subinternship. The faculty members involved were also teaching the curriculum, and were not blinded to the observation number of the handovers assessed. Students were assessed while giving patient handovers, but students receiving the information were not assessed. Students were not randomly assigned to intervention and control groups. Although the study did not constitute a randomised design, findings indicate that handover curricula are feasible and can improve performance and confidence in a real-life clinical setting.
Our goal is to

prepare

students to

provide

handovers as

PGY-1 trainees 
By acquiring

these skills

prior to

graduating,

medical

students will

hopefully be

better able to

perform patient

handovers
Based on our results, we suggest that medical schools can teach handover skills during medical students' subinternships, and should incorporate a formal handover curriculum into clinical training. By acquiring these skills prior to graduating, medical students will hopefully be better able to perform patient handovers at the beginning of their PGY-1 year, and become more confident in their skills, making the task seem less daunting. Ideally, this will improve patient care by decreasing the associated threats to patient safety.

\section{REFERENCES}

1. Antiel RM, Reed DA, Van Arendonk $\mathrm{KJ}$, Wightman SC, Hall DE, Porterfield $J R$, Horvath KD, Terhune KP, Tarpley JL, Farley DR. Effects of Duty Hour Restrictions on Core Competencies, Education, Quality of Life, and Burnout Among General Surgery Interns. JAMA Surg 2013;16:1-8.

2. Horwitz LI, Moin T, Krumholz HM, Wang L, Bradley EH. Consequences of inadequate sign-out for patient care. Arch Intern Med 2008;168:1755-1760.

3. WHO Collaborating Centre for Patient Safety Solutions. Communication during patient hand-overs. Patient Safety Solutions, Vol. 1, solution 3 . May 2007.

4. Horwitz LI, Moin T, Green ML. Development and Implementation of an Oral Sign-out Skills Curriculum. J Gen Intern Med 2007;22:1470-1474.

5. Borowitz SM, Waggoner-Fountain LA, Bass EJ, Sledd RM. Adequacy of information transferred at resident signout (inhospital handover of care): a prospective survey. Qual Saf Health Care 2008;17:6-10.

6. Cleland JA, Ross S, Miller SC, Patey R. "There is a chain of Chinese whispers...": empirical data support the call to formally teach handover to pre-qualification doctors. Qual Saf Health Care 2009;18:267-271.

7. Aschenbrener CA, Englander R. Core Entrustable Professional Activities for Entering Residency (CEPAER) AMC Spring Meetings Update 2014.
Available at: http://members.aamc. org/eweb/upload/Core\%20EPA\%20 Curriculum\%20Dev\%20Guide.pdf. Accessed on 13 October 2015.

8. Stojan JN, Schiller J, Mullan PB, Fitzgerald JT, Christner J, Ross P, Middlemas $S$, Haftel $H$, Stansfield $R$ Lypson M. Medical School Handoff Education Improves Postgraduate Trainee Performance and Confidence. Med Teach 2015;37:281-288.

9. Shaughnessy E. Pediatric Resident Sign-out Education. 2001. Available at: http://www.mededportal.org/ publication/8321. Accessed on 13 October 2015.

10. Farnan JM, Paro JA, Rodriguez RM, Reddy ST, Horwitz LI, Johnson JK, Arora VM. Hand-off education and evaluation: Piloting the observed simulated hand-off experience (OSHE). J Gen Intern Med 2010;25:129-134.

11. Held MR, Burke GS, Zalneraitis E. Pediatric residency program handover; before and after the ACGME requirement. Acad Pediat 2014;14:610-615.

12. Darbyshire D, Gordon M, Baker P. Teaching handover of care to medical students. Clin Teach 2013;10(1):32-37.

Corresponding author's contact details: Jennifer Stojan, Departments of Internal Medicine and Pediatrics, University of Michigan Hospitals, 3119 Taubman Center, SPC5376, 1500 East Medical Center Drive, Ann Arbor, MI 48109, USA. E-mail: jstojan@umich.edu

Funding: None.

Conflict of interest: None.

Acknowledgements: None.

Ethical approval: This study received ethical approval from the University of Michigan Institutional Review Board.

doi: $10.1111 /$ tct.12461 